\title{
Aspects of Exercise before or after Bariatric Surgery: A Systematic Review
}

\author{
Sjaak Pouwels ${ }^{a, b}$ Marjon Wit ${ }^{c}$ Joep A.W. Teijink ${ }^{a, b}$ Simon W. Nienhuijs ${ }^{a}$ \\ ${ }^{a}$ Department of Surgery, Catharina Hospital, Eindhoven, the Netherlands; ${ }^{b}$ Department of \\ Epidemiology, CAPHRI Research School, Maastricht University, Maastricht, the Netherlands; \\ 'Department of Physiotherapy, Catharina Hospital, Eindhoven, the Netherlands
}

\section{Key Words}

Bariatric surgery $\cdot$ Physical activity $\cdot$ Exercise $\cdot$ Weight loss

\begin{abstract}
Background: Bariatric surgery has a considerable effect on weight loss. A positive relation of exercise and weight loss has been described before. However, the mode of exercise and its timing pre- or postoperatively or a combination remains unclear. Methods: A multi-database search was conducted. Identified articles were reviewed on description of exercise, timing around a bariatric intervention, and outcome. Methodological quality of the included studies was rated using the Physiotherapy Evidence Database scale. A Cohen's kappa score assessed the level of agreement. Outcome measurements were improvement of anthropometric and physical fitness variables, operation related complications, weight regain, and quality of life. Results: A total of 8 prospective studies were included. Four focused on training before and 4 on training after a bariatric procedure. Details of exercises varied from 45 min treadmill up to full descriptive programs. Supervision was frequently included. Significant improvement was encountered for biometric results physical fitness variables. Conclusion: In the majority of reports on exercising in a (future) bariatric population, positive effects on anthropometrics, cardiovascular risk factors and physical fitness were described. However, the results were not unanimous, with a wide range of exercise programs and perioperative timing, therefore hampering adequate practical guidance.

(c) 2015 S. Karger GmbH, Freiburg
\end{abstract}

\section{Introduction}

Obesity is a major contributor to a wide variety of diseases, including diabetes, hypertension, dyslipidemia, and obstructive sleep apnea syndrome [1, 2]. Over the last decades, dietary and exercise interventions had increasing public health and governmental attention. 
Pouwels et al.: Aspects of Exercise before or after Bariatric Surgery: A Systematic Review

Nevertheless, the proportion of the population with morbid obesity gained every year [3]. The only treatment with a longstanding effect is bariatric surgery $[4,5]$. However, these interventions are no universal remedy and a considerable proportion of patients has insufficient weight loss or regain in weight over time after the operation [6].

The key elements for durable weight loss are preoperative screening, an appropriate algorithm of bariatric techniques, and, most important, a strict regime of follow-up. Followup should include medical and psychological guidance, including continuing dietary advice and maintenance of a physical exercise regimen.

There is extensive knowledge that exercise helps to gain a better physical fitness and quality of life (QoL). A Cochrane review showed a reduction of $1.5 \mathrm{~kg}$ that was contributed to exercise [7]. Another systematic review focusing on physical training and obesity found a $4 \%$ excess weight loss [8]. In their review, Egberts et al. [9] found a reduction of $3.6 \mathrm{~kg}$ related to physical exercise. In each of these three reviews, only prospective cohort studies were included as no randomized controlled trials could be identified. Weight measurement was merely self-reported, and in the majority of studies the mode of physical activity was not defined. However, the positive relationship between exercise and weight loss seems evident. The problem is; what kind/type/mode of exercise should an obese patient be advised and what about its timing - pre- or postoperatively or a combination of both? These questions were the objective of the present systematic review.

\section{Material and Methods}

A systematic search on the qualitative aspects and timing of physical exercise in bariatric surgery patients was conducted. The population of interest consisted of obese patients with a BMI $\geq 30 \mathrm{~kg} / \mathrm{m}^{2}$. The intervention of interest was exercise training compared to regular care (no specific physical exercise training program). Also included were the different modes of exercise training; those were compared to each other. Outcome measurements were: improvement of anthropometric and physical fitness variables, effect on weight, and quality of life.

Pubmed, Embase, and CINAHL were searched from the earliest date of each database up to July 2014. The search for publications was performed using the following search string: (('Bariatrics'[Mesh] OR bariatrics OR bariatric surgery OR 'Obesity, Morbid'[Mesh] OR morbid obesity)) AND ('Physical Therapy Modalities' [Mesh] OR physical therapy OR physiotherapy OR 'Exercise'[Mesh] OR exercise).

The authors MW and SP, blinded for authors and journals, separately screened and selected the studies on the basis of title and abstract. After primary selection, both authors reviewed the full text of the selected studies to determine suitability for inclusion, based on the established selection criteria.

- $\quad$ Randomized controlled trial or prospective trial.

- Patients awaiting bariatric surgical intervention or with bariatric surgery in the past.

- A description of an exercise program, defined as a regimen of physical activities, included.

- Modes of exercise training were defined as follows: strength training and/or endurance training or a combination of both. Also multimodal programs with exercise components were included.

- Registration of anthropometric and physical fitness variables, complications, effects on weight, and QoL.

- Physical fitness variables are defined as a percentage of $\mathrm{VO}_{2}$ max and/or heart rate reserve / heart rate kinetics.

In addition cross-references were screened for further eligible studies. Disagreements between the two authors were resolved by discussion and by consultation of the senior authors (JT, SN), until consensus was reached. It was presupposed to be confronted with a significant clinical heterogeneity for which a systematic review could be performed, but not a meta-analysis

The methodological quality of the included studies was rated using the Physiotherapy Evidence Database (PEDro) scale [10], which has acceptable reliability [11]. The PEDro scale consists of 11 criteria, with a maximum score of 10 (range $0-10$ ) since the first item (the specification of the eligibility criteria) is not included in the total score. Two authors (MW and SP) separately assigned PEDro scores to each included study. For rating the methodological quality, the following classification was used: a PEDro score of 4 indicated a poor methodological quality, a score of 4-5 fair quality, a score of 6-8 good quality, and a score of 
Pouwels et al.: Aspects of Exercise before or after Bariatric Surgery: A Systematic Review

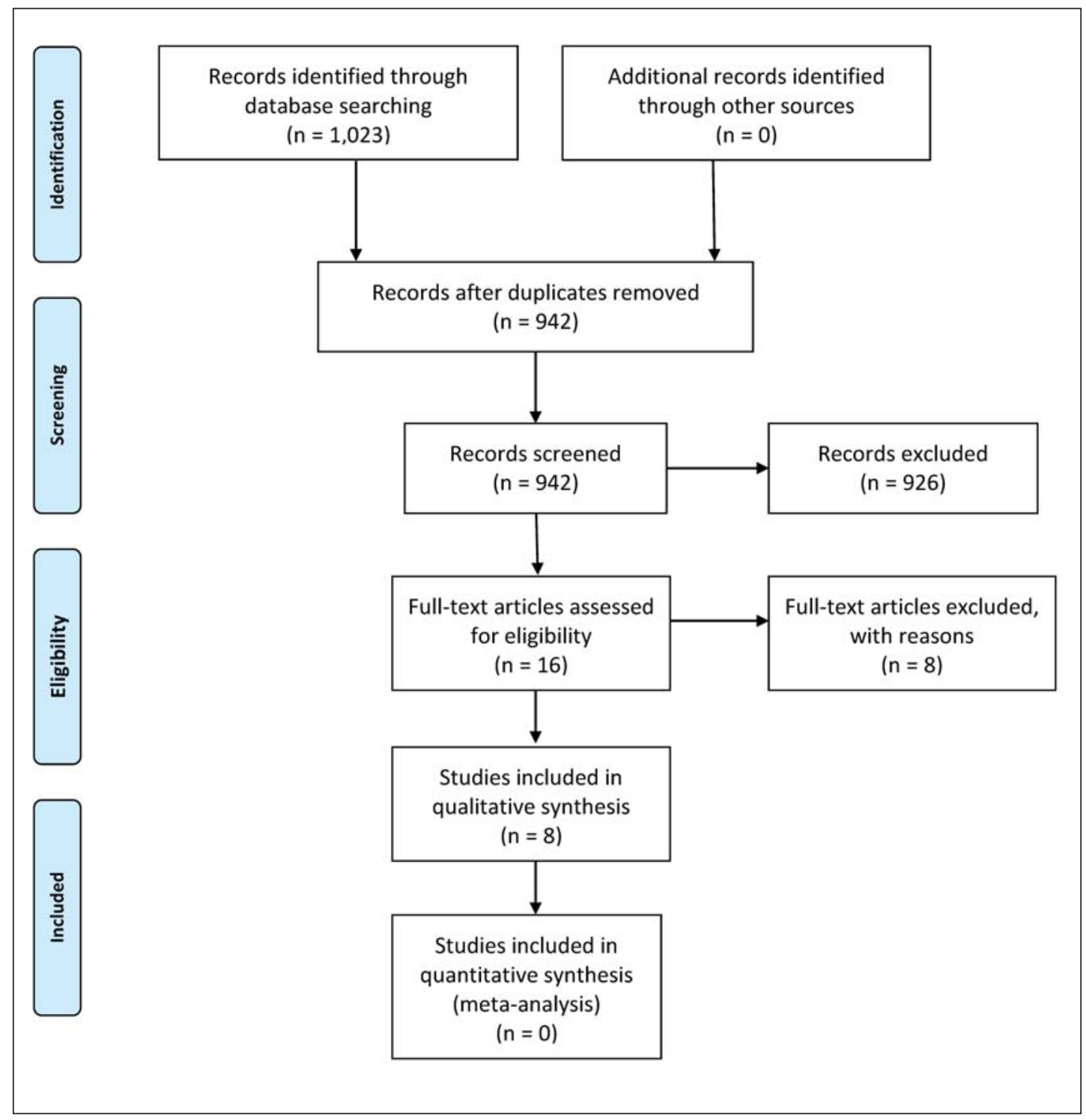

Fig. 1. PRISMA flowchart.

9-10 excellent quality [12]. A Cohen's kappa score assessed the level of agreement between the authors. The score was determined as follows: $<0.20$ poor agreement, $0.21-0.40$ fair agreement, $0.41-0.60$ moderate agreement, $0.61-0.80$ good agreement, and 0.81-1.00 very good agreement [13].

\section{Results}

The primary search produced 1,023 results, including 81 duplicates. 16 studies were identified as possibly relevant and underwent a full text critical appraisal, resulting in 8 exclusions. One study investigated exercise programs for Prader-Willi patients [14], 3 studies investigated pulmonary physiotherapy in the bariatric population [15-17], 1 publication appeared to be a case report [18], 1 was a research protocol [19], 1 article was only available in Swedish [20], and 1 article was only available in Spanish [21]. 
Pouwels et al.: Aspects of Exercise before or after Bariatric Surgery: A Systematic Review

Table 1. Methodological quality of included studies using the PEDro score [10]

\begin{tabular}{lccccccccccccc}
\hline & \multicolumn{1}{c}{ Criteria $^{\mathrm{a}}$} & & & & & & & & \\
\cline { 2 - 11 } & 1 & 2 & 3 & 4 & 5 & 6 & 7 & 8 & 9 & 10 & 11 & total \\
\hline Castello-Simoes et al., 2013 [27] & $\mathrm{x}$ & $\mathrm{x}$ & $\mathrm{x}$ & $\mathrm{x}$ & - & - & - & $\mathrm{x}$ & $\mathrm{x}$ & $\mathrm{x}$ & $\mathrm{x}$ & 7 \\
Funderburk and Callis, 2010 [23] & $\mathrm{x}$ & $\mathrm{x}$ & $\mathrm{x}$ & - & - & - & - & $\mathrm{x}$ & $\mathrm{x}$ & $\mathrm{x}$ & $\mathrm{x}$ & 6 \\
Hickey et al., 1999 [24] & $\mathrm{x}$ & - & - & $\mathrm{x}$ & - & - & - & $\mathrm{x}$ & $\mathrm{x}$ & $\mathrm{x}$ & $\mathrm{x}$ & 5 \\
Stegen et al., 2011 [28] & $\mathrm{x}$ & - & - & $\mathrm{x}$ & - & - & - & $\mathrm{x}$ & $\mathrm{x}$ & $\mathrm{x}$ & $\mathrm{x}$ & 5 \\
Baillot et al., 2013 [22] & $\mathrm{x}$ & - & - & $\mathrm{x}$ & - & - & - & $\mathrm{x}$ & $\mathrm{x}$ & $\mathrm{x}$ & $\mathrm{x}$ & 5 \\
Shah et al., 2011 [26] & $\mathrm{x}$ & $\mathrm{x}$ & $\mathrm{x}$ & $\mathrm{x}$ & - & - & - & $\mathrm{x}$ & $\mathrm{x}$ & $\mathrm{x}$ & $\mathrm{x}$ & 7 \\
Marcon et al., 2011 [25] & $\mathrm{x}$ & - & - & $\mathrm{x}$ & - & - & - & - & $\mathrm{x}$ & $\mathrm{x}$ & $\mathrm{x}$ & 4 \\
Berggren et al., 2008 [29] & $\mathrm{x}$ & - & - & $\mathrm{x}$ & - & - & - & - & $\mathrm{x}$ & $\mathrm{x}$ & $\mathrm{x}$ & 4 \\
\hline
\end{tabular}

aPEDro criteria: (1) Specification of eligibility criteria (this criterion was not counted for the final score), (2) random allocation, (3) concealed allocation, (4) prognostic similarity at baseline, (5) participant blinding, (6) therapist blinding, (7) outcome assessor blinding, (8) more than 85\% follow-up of at least one key outcome, (9) intention-to-treat analysis, (10) between or within-group statistical comparison, (11) point estimates of variability provided (10).

Figure 1 summarizes the search results. The methodological quality of the included studies ranged from moderate to good quality, as indicated by the PEDro scale (table 1). The level of agreement between reviewers (MW and SP) was reflected by a Cohen's kappa 0.78, which represents a good agreement. The key findings of the included studies are shown in table 2 for those with exercise before and in table 3 for those with exercise after bariatric surgery.

\section{Study Designs and Patient Population}

In total 4 studies with exercise before bariatric [22-25] and 4 studies with exercise after bariatric surgery [26-29] were included. There were 3 randomized controlled trials $[23,26,27]$ and 5 prospective trials $[22,24,25,28,29]$, including a patient population with a mean age ranging from 28 to 54 years and a mean BMI ranging from 40.4 to $48.7 \mathrm{~kg} / \mathrm{m}^{2}$. In the 4 studies with exercise before surgery, follow-up was done preoperatively and 7 days after surgery [24], preoperatively and 12 weeks after surgery [22, 23], or preoperatively and 24 weeks after surgery [25]. Of the 4 studies with exercise after surgery, 1 had postoperative follow-up only at 12 weeks [26] and 3 had preoperative and postoperative followup (1 week preoperatively and 4 weeks postoperatively [27], preoperatively (unknown how long) and 4 months postoperatively [28], or 1 week preoperatively and 10 days postoperatively [29]).

\section{Exercise before Bariatric Surgery}

\section{Anthropometric Variables}

Four studies reported on the effects of exercise training on the anthropometric variables. Baillot et al. [22] reported a significant reduction in weight (144.3 vs. $140.2 \mathrm{~kg} ; \mathrm{p}=0.07$ ), BMI (51.4 vs. $\left.47.2 \mathrm{~kg} / \mathrm{m}^{2} ; \mathrm{p}=0.004\right)$, neck circumference ( $42.2 \mathrm{vs} .41 .0 \mathrm{~cm} ; \mathrm{p}=0.016$ ), and fat mass (72.1 vs. $69.1 \mathrm{~kg} ; \mathrm{p}=0.026)$ after supervised exercise training in 12 patients awaiting bariatric surgery. 
Pouwels et al.: Aspects of Exercise before or after Bariatric Surgery: A Systematic Review

Table 2. Pre-bariatric surgery exercise regimes

\begin{tabular}{|c|c|c|}
\hline Study & Exercise regime & Outcome \\
\hline $\begin{array}{l}\text { Baillot et al., } 2013 \\
{[22]}\end{array}$ & $\begin{array}{l}\text { The physical exercise sessions consisted of: } \\
10 \text { min of warm up, } 30 \text { min of endurance activity } \\
\text { (treadmill, walking circuit), 20-30 min of strength } \\
\text { exercises, } 10 \text { min of cooling-down. } \\
\text { Supervision by a physical activity specialist and/or } \\
\text { completed independently at home. } \\
\text { The intensity of the endurance training was determined } \\
\text { using the HRR method and using data from the } \\
\text { previously performed symptom limited cardiac } \\
\text { treadmill test. The progression of endurance intensity } \\
\text { and duration according to physical fitness and physical } \\
\text { activity. Electronic pulse monitors (Polar F4 } 4^{\mathrm{T}} \text { ) were } \\
\text { used to control endurance exercise intensity during } \\
\text { supervised sessions and at home. } \\
\text { Strength exercises: } \\
\text { Performed with small equipment easily available at } \\
\text { home: dumbbells, elastic bands, and sticks. Three mini- } \\
\text { circuits (upper body, lower body, and trunk) repeated } \\
\text { by subjects according to their prescription. }\end{array}$ & $\begin{array}{l}6 M W T \text { distance, } m: \\
\text { before: } 464(412-501) \\
\text { after: } 492(450-531) \\
(\mathrm{p}=0.05) \\
\text { Arm Curl Test }(n): \\
\text { before: } 22(16.7-26) \\
\text { after: } 26(21-31) \\
(\mathrm{p}=0.01)\end{array}$ \\
\hline $\begin{array}{l}\text { Funderburk and } \\
\text { Callis, } 2010 \text { [23] }\end{array}$ & $\begin{array}{l}\text { The intervention group did two sessions of } 60 \text { min of } \\
\text { aquatic exercises including endurance and strength } \\
\text { exercises for } 12 \text { weeks }\end{array}$ & $\begin{array}{l}\text { Weight loss: } \\
\text { I: }+5.0 \mathrm{~kg} \\
\mathrm{C}:-2.3 \mathrm{~kg} \\
\text { SBP and DBP: } \\
\mathrm{I}:+34 \mathrm{~mm} \mathrm{Hg} \text { and }-4 \mathrm{~mm} \mathrm{Hg} \\
\mathrm{C}:-57 \mathrm{~mm} \mathrm{Hg} \text { and } 0 \mathrm{~mm} \mathrm{Hg} \\
6 M W T: \\
\mathrm{I}:+10.4 \mathrm{~m} \\
\mathrm{C}:+40.2 \mathrm{~m} \\
\text { QoL and depression score: } \\
\text { No significant post intervention difference } \\
\text { between groups } \\
\text { I: decrease in bodily pain and depression } \\
\text { score (p< } 0.05 \text { ) } \\
\text { C: Increase in mental health (p<0.05) }\end{array}$ \\
\hline $\begin{array}{l}\text { Hickey et al., } 1999 \\
{[24]}\end{array}$ & $\begin{array}{l}7 \text { days of supervised endurance training at } 60 \% \text { of } \mathrm{VO}_{2} \\
\text { peak. Each session was } 60 \mathrm{~min}\end{array}$ & $\begin{array}{l}\text { Decrease of fasting plasma insulin }(-41.7 \\
\text { pmol/; } \mathrm{p}<0.05) \\
\text { No significant change in body weight, \% fat } \\
\text { mass, glucose and blood lipid concentration } \\
\text { after intervention } \\
\text { No significant change in } \mathrm{VO}_{2} \text { peak after } \\
\text { exercise intervention }\end{array}$ \\
\hline
\end{tabular}

Table 2 continued on next page

Funderburk and Callis [23] showed a reduction in body weight of $5.0 \mathrm{~kg}$ after 12 weeks of supervised aquatic exercises in the intervention group and of $2.3 \mathrm{~kg}$ in the control group. It was not reported whether this is a significant decrease. There was no significant change in body weight and free fat mass after a 7-day exercise regimen in a study by Hickey et al. [24]. In contrast, Marcon et al. [25] found a significant decrease in body weight $(-5.3 \mathrm{~kg} ; \mathrm{p}<$ $0.001)$ and BMI $\left(-1.9 \mathrm{~kg} / \mathrm{m}^{2} ; \mathrm{p}<0.001\right)$ after a 24 -week supervised low-intensity endurance training. 
Pouwels et al.: Aspects of Exercise before or after Bariatric Surgery: A Systematic Review

Table 2. Continued

\begin{tabular}{|c|c|c|}
\hline Study & Exercise regime & Outcome \\
\hline $\begin{array}{l}\text { Marcon et al., } 2011 \\
\text { [25] }\end{array}$ & $\begin{array}{l}24 \text { weeks of supervised low intensity endurance } \\
\text { training. One session per week, consisting of } 209 \text { min of } \\
\text { exercise and } 10 \text { min stretching }\end{array}$ & $\begin{array}{l}\text { Body weight and BMI } \\
\text { decreased body weight }(-5.3 \mathrm{~kg} ; \mathrm{p}<0.001) \\
\text { decreased BMI }\left(-1.9 \mathrm{~kg} / \mathrm{m}^{2} ; \mathrm{p}<0.001\right) \\
\text { SBP and DBP: } \\
\text { decrease in SBP }(-23.8 \mathrm{~mm} \mathrm{Hg} \text {; }=0.007) \\
\text { and DBP }(-14.4 \mathrm{~mm} \mathrm{Hg} \mathrm{p}=0.001) \\
\text { Lipids and glucose: } \\
\text { improvement of TC }(-23.0 \mathrm{mg} / \mathrm{dl}), \mathrm{HDL}-\mathrm{C} \\
(+1.7 \mathrm{mg} / \mathrm{dl}), \mathrm{LDL}-\mathrm{C}(-2.3 \mathrm{mg} / \mathrm{dl}), \mathrm{TG}(-26.7 \\
\mathrm{mg} / \mathrm{dl}) \text { and glucose }(-17.2 \mathrm{mg} / \mathrm{dl}): \text { for all } \\
\mathrm{p}<0.007 \\
6 M W T \text { : } \\
\text { improved walking distance }(+69.8 \mathrm{~m} ; \mathrm{p}< \\
0.0001)\end{array}$ \\
\hline
\end{tabular}

HRR = Heart rate reserve; $\mathrm{I}=$ intervention group; $\mathrm{C}=$ control group; $6 \mathrm{MWT}=6$ - min walking test; $\mathrm{n}=$ number, $\mathrm{SBP}=$ systolic blood pressure; $\mathrm{DBP}=$ diastolic blood pressure; $\mathrm{VO}_{2}$ peak = maximum oxygen consumption; $\mathrm{TC}=$ total cholesterol, $\mathrm{TG}=$ triglycerides.

Table 3. Post-bariatric surgery exercise regimes

\begin{tabular}{|c|c|c|}
\hline Study & Exercise regime & Outcome \\
\hline $\begin{array}{l}\text { Shah et al., } 2011 \\
\text { [26] }\end{array}$ & $\begin{array}{l}\text { Energy expenditure } \geq 2,000 \mathrm{kcal} / \text { week in moderate- } \\
\text { intensity aerobic exercise at } 60-70 \% \text { of maximal } \\
\text { oxygen consumption }\left(\mathrm{VO}_{2} \mathrm{max}\right) \text {. } \\
\text { The subjects were instructed to achieve these goals } \\
\text { gradually and were asked to expend } 500 \mathrm{kcal} \text { during the } \\
\text { first week and increase by } 500 \mathrm{kcal} \text { every week until } \\
\text { they achieved their goal of } \geq 2,000 \mathrm{kcal} / \text { week. } \\
\text { Each subject was asked to exercise on the treadmill at a } \\
\text { certain speed and grade and on the cycle ergometer or } \\
\text { rowing machine at a particular wattage that would } \\
\text { correspond to } 60-70 \% \text { of her/his measured } \mathrm{VO}_{2} \text { max. } \\
\text { Subjects who preferred to walk outside or on the } \\
\text { walking track were asked to measure the distance that } \\
\text { they walked and asked to complete this distance in a } \\
\text { time period to achieve a pace associated with an } \\
\text { intensity of } 60-70 \% \text { of the measured VO } \mathrm{O}_{2} \text { max. } \\
\text { The subjects were asked to exercise at least } 5 \text { days a } \\
\text { week and to increase the intensity of exercise to remain } \\
\text { the same level of exertion after each training. } \\
\text { The exercise was partially supervised and the subjects } \\
\text { were asked to come to the fitness center at least once or } \\
\text { twice a week. } \\
\text { Energy expenditure per week was calculated } \\
\text { approximately from the work data shown on the } \\
\text { exercise equipment and from the duration and distance } \\
\text { of walking relative to body weight. } \\
\text { Exercise away from the fitness center was monitored by } \\
\text { asking the subjects to keep an exercise diary and/or } \\
\text { using heart rate monitors. }\end{array}$ & $\begin{array}{l}\text { Energy expenditure (moderate physical } \\
\text { activity) (kcal/kg/day): } \\
\text { IG: baseline } 1.1(0-5.8), \\
6 \text { weeks } 3.5(0.4-8.2) ; \\
\text { p < } 0.02 \text {, } \\
12 \text { weeks } 4.1(0-15.0) ; \\
\text { p }<0.0001 \\
\text { Time spent (moderate physical activity) } \\
\text { (h/day): } \\
\text { IG: baseline } 0.3(0-1.5), \\
6 \text { weeks } 0.9(0.1-2.1) ; \\
\text { p < } 0.02 \\
12 \text { weeks } 1.0(0-3.8), \\
\text { p }<0.0001\end{array}$ \\
\hline
\end{tabular}


Pouwels et al.: Aspects of Exercise before or after Bariatric Surgery: A Systematic Review

Table 3. Continued

\begin{tabular}{|c|c|c|}
\hline Study & Exercise regime & Outcome \\
\hline $\begin{array}{l}\text { Castello-Simoes } \\
\text { et al., } 2013 \text { [27] }\end{array}$ & $\begin{array}{l}\text { Start of aerobic training } 48 \mathrm{~h} \text { after maximal exercise test. } \\
\text { Session duration } 1 \mathrm{~h} \text { on alternate days, } 3 \text { times a week, for } 12 \text { weeks, } \\
\text { totaling } 36 \text { sessions. } \\
\text { A session consisted of the following: } \\
\text { initial 5-min stretching of upper and lower limbs and diaphragmatic } \\
\text { breathing. } \\
5 \text {-min warm up on a treadmill at } 3 \mathrm{~km} / \mathrm{h} \text {. } \\
40 \text { min of exercise on a treadmill with speed and inclination varying } \\
\text { according to the behavior of HR, separated in } 4 \text { steps; } \\
\text { Step 1: intensity of exercise in which the HR remained at } 50 \% \text { of HR } \\
\text { peak, reached in maximal exercise testing. } \\
\text { Step 2: } 60 \% \text { of HR peak. } \\
\text { Step 3: } 70 \% \text { of HR peak. } \\
\text { Step } 4: \text { Maintaining } 70 \% \text { of the HR peak. } \\
1 \text { min recovery at } 3 \mathrm{~km} / \mathrm{h} \text {. } \\
10 \text { min of the same initial stretching and diaphragmatic breathing. } \\
\text { HR and blood pressure were obtained at the beginning of the session, } \\
\text { at the end of each step, recovery and at the end of the session. }\end{array}$ & $\begin{array}{l}\text { Lung function (FVC) } \\
\text { TG: } \\
\quad \text { BGBS } 94.0 \pm 3.1 \\
\text { 4GBS } 101.0 \pm 2.5 \\
\text { CG: } \\
\quad \text { BGBS } 99.0 \pm 2.4 \\
\quad \text { 4GBS } 100.0 \pm 3.7 \\
\text { EG: } 100 \pm 4.0 \\
\text { Mean HR (beats/min) } \\
\text { TG: } \\
\quad \text { BGBS } 132.3 \pm 6.0 \\
\text { 4GBS } 124 \pm 5.9 \\
\text { CG: } \\
\quad \text { BGBS } 138.2 \pm 3.7 \\
\text { 4GBS } 125 \pm 3.9 \\
\text { EG: } 135.5 \pm 3.5 \\
\text { 6MWT walking distance, } m \\
\text { TG: } \\
\quad \text { BGBS } 470.0 \pm 23.9 \\
\text { 4GBS } 515.0 \pm 14.0 \\
\text { CG: } \\
\quad \text { BGBS } 453.0 \pm 29.0 \\
\text { 4GBS } 505.0 \pm 10.9 \\
\text { EG: } 641.0 \pm 10.4 \\
\text { Dyspnea (0-10) } \\
\text { TG: } \\
\text { BGBS } 5.8 \pm 0.6 \\
\text { 4GBS } 2.7 \pm 0.8 \\
\text { CG: } \\
\text { BGBS } 5.9 \pm 0.5 \\
\text { 4GBS } 4.5 \pm 0.9 \\
\text { EG: } 2.8 \pm 0.9\end{array}$ \\
\hline
\end{tabular}

Table 3 continued on next page

\section{Compliance}

Baillot et al. [22] had a high compliance to the preoperative exercise training program. They proposed 35 supervised exercise sessions in 12 weeks. Seven patients completed the full program, and 5 had bariatric surgery before the end of the program. With median $57.3 \%$ (32.5-77.6\%) and 64.5\% (47.5-79.9\%), the attendance to the supervised exercise sessions and the total exercise sessions, respectively, was satisfactory.

\section{Blood Pressure}

After 12 weeks of aquatic exercises, Funderburk and Callis [23] found an increase in systolic blood pressure and a decrease in diastolic blood pressure in the intervention group (+34 $\mathrm{mm} \mathrm{Hg}$ and $-4 \mathrm{~mm} \mathrm{Hg}$, respectively). In the control group, there was a decrease of the systolic blood pressure $(-57 \mathrm{~mm} \mathrm{Hg})$ while the diastolic blood pressure remained unchanged [23]. After 24 weeks of supervised endurance training, Marcon et al. [25] reported a significant decrease in systolic and diastolic blood pressure $(-23.8 \mathrm{~mm} \mathrm{Hg}(\mathrm{p}=0.007)$ and -14.4 $\mathrm{mm} \mathrm{Hg}(\mathrm{p}=0.001)$ respectively $)$. 
Pouwels et al.: Aspects of Exercise before or after Bariatric Surgery: A Systematic Review

Table 3. Continued

\begin{tabular}{|c|c|c|}
\hline Study & Exercise regime & Outcome \\
\hline $\begin{array}{l}\text { Stegen et al., } 2011 \\
\text { [28] }\end{array}$ & $\begin{array}{l}\text { Strength exercises were performed using stack-weight equipment } \\
\text { (elbow flexion and extension and knee flexion and extension). } \\
\text { Intensity of strength training was calculated from one repetition } \\
\text { maximum (1RM) values. } \\
\text { The starting level was } 60 \% \text { of } 1 \mathrm{RM} \text {, which increased up to } 75 \% \text { of } \\
\text { 1RM. Patients were habituated to the exercises and equipment during } \\
\text { the first three training sessions. } \\
\text { In the next } 15 \text { sessions, two sets of } 15 \text { repetitions at } 60 \% \text { of } 1 \mathrm{RM} \text { were } \\
\text { done. } \\
\text { In the final } 18 \text { sessions, three sets of } 10 \text { repetitions at } 75 \% \text { were done. } \\
\text { Resting periods between repetition sets were approximately } 60 \mathrm{~s} \text {. } \\
\text { Endurance training consisted of cycling (10 min), walking (10 min), } \\
\text { and stepping (10 min). Exercise intensity was initially set at } 60 \% \text { of } \\
\text { heart rate reserve (HRR, defined as the difference between resting } \\
\text { heart rate and peak heart rate) and was gradually increased up to } \\
75 \% \text { of HRR at the end of the training period. Stationary bicycles, } \\
\text { treadmills, and steppers were used in a rehabilitation training room. }\end{array}$ & $\begin{array}{l}\text { Dynamic muscle strength in } \\
\mathrm{kg}(4 \text { months postoperatively): } \\
\text { Quadriceps: } \\
\text { IG: } 58.0 \pm 25.6 \\
\text { CG: } 45.9 \pm 25.1 \\
\text { (p }=0.002 \text { ) } \\
\text { Biceps: } \\
\text { IG: } 25.9 \pm 13.0 \\
\text { CG: } 20.8 \pm 8.8 \\
\text { (p }=0.001 \text { ) } \\
\text { Triceps: } \\
\text { IG: } 30.7 \pm 23.0 \\
\text { CG: } 22.0 \pm 6.6 \\
\text { (p }=0.038 \text { ) }\end{array}$ \\
\hline $\begin{array}{l}\text { Berggren et al., } \\
2008 \text { [29] }\end{array}$ & $\begin{array}{l}10 \text { consecutive days of endurance-oriented exercise training. } \\
\text { An incremental, maximal stress test was initially performed to screen } \\
\text { for underlying cardiovascular disease and determine the workload } \\
\text { (\%peak oxygen consumption and heart rate peak) for the exercise } \\
\text { training. } \\
\mathrm{VO}_{2} \text { peak was determined on an electronically braked cycle ergometer } \\
\text { in the upright position, with oxygen consumption measured via open- } \\
\text { circuit spirometry. } \\
\text { The training program was based upon previous exercise prescriptions } \\
\text { that improved whole body fat oxidation or increased mitochondrial } \\
\text { content. } \\
\text { Participants exercised } 60 \text { min/day at } 70 \% \mathrm{VO}_{2} \text { peak for } 10 \\
\text { consecutive days on a cycle ergometer. } \\
\text { All training was performed under direct supervision. } \\
\text { Subjects were initially permitted to take a rest break ( } 5 \text { min) during } \\
\text { exercise; by day } 5 \text { all subjects exercised continuously. }\end{array}$ & $\begin{array}{l}\text { Muscle fatty acid oxidation: } \\
\text { Lean subjects }+1.7 \text {-fold } \\
\text { increase } \\
\text { Obese subjects }+1.8 \text {-fold } \\
\text { increase } \\
\text { Previously extreme obese } \\
\text { subjects after weight loss } \\
+2.6 \text {-fold increase }\end{array}$ \\
\hline
\end{tabular}

GBS = Gastric bypass; $\mathrm{TG}$ = trained group; $\mathrm{CG}=$ control group; $\mathrm{EG}=$ eutrophic group; $\mathrm{BGBS}=$ before gastric bypass surgery; 4GBS = 4 months after gastric bypass surgery; $\mathrm{W}=$ weight; $6 \mathrm{MWT}=6$ - min walking test; $\mathrm{FVC}=$ forced vital capacity; $\mathrm{HR}=$ heart rate; $1 \mathrm{RM}$ = one repetition maximum; $\mathrm{HRR}$ = heart rate reserve; $\mathrm{IG}=$ intervention group.

\section{Cardiovascular Risk Factors and Inflammation}

Hickey et al. [24] reported a significant decrease of fasting plasma insulin ( $-41.7 \mathrm{pmol} / \mathrm{l})$ after 7 days of supervised exercise training, 60 min per day. There were no significant changes in glucose and blood lipid concentration after the exercise intervention [24].

In the study by Marcon et al. [25], a significant improvement was seen in blood lipid and glucose concentrations after 24 weeks of supervised endurance training (total cholesterol $-23.0 \mathrm{mg} / \mathrm{dl}$; HDL-cholesterol $+1.7 \mathrm{mg} / \mathrm{dl}$, LDL-cholesterol $-2.3 \mathrm{mg} / \mathrm{dl}$, triglycerides -26.7 $\mathrm{mg} / \mathrm{dl}$, glucose $-17.2 \mathrm{mg} / \mathrm{dl}$ (for all $\mathrm{p}<0.007$ )). 
Pouwels et al.: Aspects of Exercise before or after Bariatric Surgery: A Systematic Review

Table 4. Common findings

\begin{tabular}{|c|c|c|c|c|c|c|c|c|}
\hline & $\begin{array}{l}\text { Shah } \\
\text { et al,. [26] }\end{array}$ & $\begin{array}{l}\text { Castello-Simoes } \\
\text { et al., [27] }\end{array}$ & $\begin{array}{l}\text { Stegen } \\
\text { et al. [28] }\end{array}$ & $\begin{array}{l}\text { Baillot } \\
\text { et al., [22] }\end{array}$ & $\begin{array}{l}\text { Funderburk } \\
\text { and Callis, [23] }\end{array}$ & $\begin{array}{l}\text { Berggren } \\
\text { et al., [29] }\end{array}$ & $\begin{array}{l}\text { Hickey } \\
\text { et al., [24] }\end{array}$ & $\begin{array}{l}\text { Marcon } \\
\text { et al., [25] }\end{array}$ \\
\hline Duration, weeks & 12 & 12 & 16 & 12 & 12 & 2 & 1 & 24 \\
\hline Intensity & $60-70 \% \mathrm{VO}_{2} \max$ & $60-70 \% \mathrm{HR}$ & $60-75 \% \mathrm{HR} / \mathrm{RM}$ & $55-85 \%$ of HRR & $\mathrm{x}$ & $70 \% \mathrm{VO}_{2} \max$ & $65 \% \mathrm{VO}_{2}$ peak & $\mathrm{x}$ \\
\hline Supervision & partial & whole & whole & partial & whole & $\mathrm{x}$ & whole & whole \\
\hline Timing bariatric surgery & post & post & post & pre & pre & post & pre & pre \\
\hline
\end{tabular}

$\mathrm{HR}=$ Heart rate; HRR = heart rate reserve; $\mathrm{RM}=$ repeated measurements; $2 \mathrm{KmWT}=2$-km walking test; $\mathrm{x}=\mathrm{unknown}$.

\section{Physical Fitness and Functional Capacity}

Baillot et al. [22] found that all 12 patients completed the baseline symptom limited treadmill test with a median duration of $11.5 \mathrm{~min}$ (11.1-12.4 min). No major cardiac complication was noted during or after the test. The 6-min walk test distance, the time of the halfsquat test, and the number of flexion during the arm curl test were all significantly $(p<0.05)$ increased after the preoperative exercise program [22].

Funderburk and Callis [23] showed an increase in the 6-min walking test distance of 10.4 $m$ after 12 weeks of aquatic exercises, but strangely the control group showed an increase of $40.2 \mathrm{~m}$. After 24 weeks, Marcon et al. [25] also saw an improvement of the 6-min walking test distance (+69.8 m; $<$ 0.0001).

\section{Aerobic Capacity}

Hickey and coworkers [24] reported that after 7 days of supervised exercise there was no significant difference in maximal oxygen uptake (which was measured by $\mathrm{VO}_{2}$ peak) indicating that there is no increase in physical fitness.

\section{QoL and Satisfaction}

Baillot et al. [22] showed that each of their 12 patients who were in the exercise program improved at least one level for endurance training and two levels for strength training. This increase appeared to be greater in the patients who trained longer. All patients were satisfied by the coaching and the advices given by the exercise professionals [22].

Also the total health-related QoL significantly improved after the exercise intervention $(p=0.012)$. On the domains of emotions, social interaction and sexual life they also noted a significant improvement ( $p=0.002, p=0.025$ and $p=0.003$, respectively) [22]. Unfortunately, no significant change was seen in symptoms $(p=0.25)$, activity/mobility $(p=0.07)$, and personal hygiene/clothing $(\mathrm{p}=0.078)$ scores. [22]

Measured by the Short Form 36 (SF-36) questionnaire and the Beck Depression inventory, Funderburk and Callis [23] found no significant postintervention difference between groups. In the aquatic exercise group, there was a significant decrease in bodily pain and a significant decrease of the depression score after 12 weeks $(\mathrm{p}<0.05)$. In the control group, there was a significant increase in mental health $(\mathrm{p}<0.05)[23]$.

\section{Exercise after Bariatric Surgery}

\section{Anthropometric Variables}

Four studies reported on the effects of exercise training on the anthropometric variables.

Stegen et al. [28] investigated the effect of an exercise program after gastric bypass surgery and found that both groups (gastric bypass + exercise training $(\mathrm{GB}+\mathrm{E})$ compared with 
Pouwels et al.: Aspects of Exercise before or after Bariatric Surgery: A Systematic Review

gastric bypass only (GB)) had the same decrease 4 months postoperatively with regard to weight (GB -26.6 $\pm 14.6 \mathrm{~kg} ; \mathrm{GB}+\mathrm{E}-22.7 \pm 5.7 \mathrm{~kg}$ ), $\mathrm{BMI}\left(\mathrm{GB}-8.3 \pm 4.1 \mathrm{~kg} / \mathrm{m}^{2} ; \mathrm{GB}+\mathrm{E}-8.1 \pm 2.5\right.$ $\mathrm{kg} / \mathrm{m}^{2}$ ), and waist circumference (GB $-20.3 \pm 11.6 \mathrm{~cm} ; \mathrm{GB}+\mathrm{E}-17.2 \pm 8.1 \mathrm{~cm}$ ) [28].

Castello-Simoes et al. [27] investigated a post-bariatric training program and used three groups: a trained group (TG), a eutrophic group (EG) and a control group (CG). They found that there was a significant reduction in weight (TG: before $115.0 \pm 6.9 \mathrm{~kg}$; after $92.0 \pm 5.1 \mathrm{~kg}$, CG: before $113.0 \pm 4.7 \mathrm{~kg}$, after $89.0 \pm 3.4 \mathrm{~kg}$ ) and BMI (TG: before $45.5 \pm 1.7 \mathrm{~kg} / \mathrm{m}^{2}$; after 36.5 $\pm 1.3 \mathrm{~kg} / \mathrm{m}^{2}$, CG: before $43.6 \pm 1 \mathrm{~kg} / \mathrm{m}^{2}$, after $34.2 \pm 1.1 \mathrm{~kg} / \mathrm{m}^{2}$ ) in TG and CG 4 months after bariatric surgery compared to the preoperative values [27].

Berggren and colleagues [29] investigated the skeletal muscle lipid oxidation before and after 10 days of endurance orientated exercise training. They found a significant weight loss after 10 days of exercise $(\mathrm{p}<0.05)$ [29].

Shah et al. [26] investigated a high-volume exercise program in 20 patients and found that in both the exercise group and the control group there was a significant reduction in body weight and hip circumference after 12 weeks (compared to baseline values).

Cardiovascular Risk Factors and Inflammation

In contrast to the above mentioned, Shah et al. [26] found no difference in cardiovascular risk factors after a high-volume exercise training program compared to the control group.

Physical Fitness and Functional Capacity

Castello-Simoes et al. [27] reported a significant increase in the 6-min walking test distance after exercise training and bariatric surgery ( $470 \pm 23.9$ vs. $515.0 \pm 14.0 \mathrm{~m}$ ). Shah et al. [26] found a significantly increased energy expenditure and time spent on exercise in highvolume exercise group per day.

\section{Aerobic Capacity}

In a maximal bicycle ergometer test before bariatric surgery, Stegen et al. [28] found that both groups (GB (gastric bypass only) and GB+E (gastric bypass and postoperative exercise program) reached their ventilator anaerobic threshold (VAT) at the power (GB $=93 \pm 24 \mathrm{~W}$; $\mathrm{GB}+\mathrm{E}=90 \pm 24 \mathrm{~W}$ ) with an equal time of occurrence $(\mathrm{GB}=270 \pm 107 \mathrm{~s} ; \mathrm{GB}+\mathrm{E}=266 \pm 133 \mathrm{~s})$ [28]. Gastric bypass surgery did not improve time of occurrence of VAT and power at VAT. When patients followed an exercise program (GB+E group) postoperatively, the time of occurrence of VAT was delayed (349 \pm 19 s) [28]. Also Stegen and colleagues [28] registered the peak exercise parameters. In the preoperative phase, morbidly obese patients reached a peak oxygen uptake of $17.4 \pm 4.9 \mathrm{ml} / \mathrm{kg} / \mathrm{min}(\mathrm{GB})$ and $17.6 \pm 3.2 \mathrm{ml} / \mathrm{kg} / \mathrm{min}(\mathrm{GB}+\mathrm{E})$. Unfortunately, absolute peak oxygen uptake and power did not improve 4 months after an intensive exercise program, nor by bariatric surgery.

Castello-Simoes et al. [27] reported a significant increase of the predicted forced vital capacity $(94.0 \pm 3.1 \mathrm{vs} .101 .0 \pm 2.5)$ in the trained group 4 months after bariatric surgery [27] In the same group there was a significant reduction of the dyspnea score (5.8 \pm 0.6 vs. $2.7 \pm$ 0.8) 4 months after bariatric surgery.

\section{Muscle Strength}

Stegen et al. [28] found that the untrained patients (who only had a GB) had a decrease in dynamic muscle strength 4 months postoperatively. They have lost $16 \%$ of their quadriceps strength, $36 \%$ of their biceps strength, and 39\% of triceps strength. Patients who had a GB followed by a postoperative exercise program prevented this decrease. Biceps $(21.8 \pm$ 8.0 vs. $25.9 \pm 13.0 \mathrm{~kg})$ and triceps $(24.3 \pm 10.1$ vs. $30.7 \pm 23.0 \mathrm{~kg})$ strength were preserved, and both hamstrings and quadriceps strength increased (by $72 \%$ and $27 \%$, respectively) due 
Pouwels et al.: Aspects of Exercise before or after Bariatric Surgery: A Systematic Review

to the exercise program [28]. Static muscle strength, which is measured as handgrip strength, decreased in both groups 4 months after GB surgery (GB 18\%, GB + exercise 7\%). Muscle fatigue was neither influenced by GB surgery nor by an additional exercise training program [28].

\section{Fatty Acid Oxidation}

Berggren et al. [29] studied the effect of weight loss through exercise training on the muscle fatty acid oxidation. Muscle fatty acid oxidation in extremely obese women who had lost weight (approximately $50 \mathrm{~kg}$ ) was compared with that of extremely obese and lean individuals [29]. There was no difference in muscle fatty acid oxidation between extremely obese persons and the weight loss group. Fatty acid oxidation was depressed compared with the lean individuals $(-45 \%$; $p<0.05)$. In contrast, 10 days of exercise training increased fatty acid oxidation in the skeletal muscle of lean, obese and previously extreme obese subjects after weight loss by the factor of $1.7,1.8$ and 2.6, respectively [29].

\section{QoL and Satisfaction}

Shah et al. [26] reported a significant improvement in the high-volume exercise group with respect to the health-related QoL in several domains including physical function ( $\mathrm{p}=$ $0.049)$, self-esteem $(p=0.0002)$, sexual life $(p=0.02)$, public distress $(p=0.003)$, and the total score $(p=0.0004)$ over 12 weeks. The control group showed a significant improvement in self-esteem ( $p=0.004)$, sexual life ( $p=0.04)$, work (or daily activities) $(p=0.04)$, and the total score $(p=0.012)$. [26] There was no group-by-week interaction for any of the scales, except for self-esteem, which was approximately $p=0.05$. The data from the SF-36 questionnaire showed that there was no group-by-week interaction for any of the scales, but the highvolume exercise group reported a significant improvement in emotional wellbeing ( $p=$ $0.001)$, energy levels $(p=0.0002)$, and mental QOL total score $(p=0.006)$ over 12 weeks, whereas QoL in the control group did not change [26].

\section{Discussion}

Considering the great value assigned to exercise, a search for evidence provided a relatively little number of prospective studies addressing this subject in relation to bariatric surgery. In the majority of reports a positive effect on anthropometrics, cardiovascular risk factors, and physical fitness was described. However, the results were not unanimous, with a wide range of exercise programs and perioperative timing, therefore hampering adequate practical guidance. Simplifying the common findings, an exercise program lasts for a median of 12 weeks, has an intensity of median $65 \%$ peak heart rate $/ \mathrm{VO}_{2}$ max, and is at least partially supervised (table 4).

Two systematic reviews [30,31] assessed the impact of physical exercise and fitness in obese individuals, but without an in-depth analysis of the perioperative timing and the type of exercise needed to improve health in the bariatric population. The results of exercise in terms of weight loss and changes of other anthropometric variables have been described before [1-3]. However the type of exercise used to achieve this weight loss was not specified/ given in detail. These details could be relevant as exercise regimes can include endurance training, strength training, or combinations of both components. Unfortunately, it is difficult to assess the appropriate type and amount of physical activity for the bariatric surgical patient. It is unclear if preoperative exercise has the same effect as postoperative exercise. Also there is no uniformity with regard to the outcome variables, and little is known about the effect of exercise programs on the weight regain after bariatric surgical interventions. 
Pouwels et al.: Aspects of Exercise before or after Bariatric Surgery: A Systematic Review

Nevertheless, it is known that exercise results in significant changes of anthropometric parameters [22-29] and greater weight loss than bariatric surgery alone [7-9].

Exercise training demonstrates favorable effects on body composition, blood pressure control, insulin sensitivity, inflammation biomarkers, and subclinical carotid atherosclerosis (CIMT). These effects have been associated with evidence of removal of oxidized phospholipids from the vessel wall, stabilization of atherosclerosis and positive changes in LDLcholesterol [32]. These changes have a strong correlation with increase in vascular function and regression in the burden of atherosclerosis [33]. Ahmadi et al. [34] showed that the CIMT decrease was significantly greater in response to a 7-month exercise program than statin or niacin therapies in the ARBITER 6 trial [35]. In other words, exercise training reduces cardiovascular risk in obese individuals.

Bariatric surgery is the only longstanding intervention when conservative therapy fails to succeed. However, bariatric surgery also has consequences. One of them is a decrease of dynamic muscle strength after the operation [28]. A possible explanation is the decrease of muscle mass after the operation. In the study of Stegen et al. [28], the untrained patients lost a total of $7.6 \mathrm{~kg}$ of muscle mass through bariatric surgery; that is $29.7 \%$ of the total body weight lost $(-26.6 \mathrm{~kg})$.

Reviews by Stiegler and Cunliffe [36] and Chaston et al. [37] confirmed the positive correlation between weight loss and fat-free mass loss (FFML). Very low caloric diets result in a greater FFML compared to moderate caloric diets. Bariatric surgery results in greater FFML than very low caloric diets. Webster et al. [38] found that the FFML should not exceed the $22 \%$ of the total weight loss because of the function in resting metabolic rate, thermoregulation, oxidative capacity of the body, and weight management. Exercise training can attenuate muscle atrophy and can maintain FFML during weight loss [36, 37], but the value of a perioperative exercise program for bariatric surgery has not been investigated.

It can be debated whether or not decrease of muscle strength is a problem for morbidly obese patients after weight loss. It is well known that obese individuals have higher absolute muscle strength compared to lean subjects, but there is lower relative muscle strength in terms of total body weight [39-42]. This gives patients an impaired functional capacity, which is due to the fact that more strength is needed to handle a heavier body. Therefore, it might be important to prevent a decrease in muscle strength after bariatric surgery. However, when investigating muscle changes before and after bariatric surgery, several factors have to be taken into account. One of them is the type of bariatric surgery. Stegen and coworkers [28] included only patients who have undergone GB surgery. To our knowledge it is unknown whether there are differences in muscle loss between different types of bariatric surgery (e.g. GB surgery compared to sleeve gastrectomy). Moreover, the patient compliance must also be studied, i.e., whether or not patients followed the dietary instructions ((re)substitution of proteins, vitamins and minerals) [36-38]. None of these data were measured in the included studies.

It is known that obese patients have a reduced functional capacity and walking distance compared to lean subjects [43]. Tompkins and colleagues [44] showed that bariatric surgery leads to an improvement of approximately $75 \%$ in functional capacity and walking capacity 6 months after the operation. Weight loss (especially loss of body fat) makes walking less exhausting which could be demonstrated by a decreased rate of exertion and heart frequency at the end of the 6-min walking test $[27,28]$. Important predictors are not only the percentage of body fat but also the maximum of oxygen uptake $\left(\mathrm{VO}_{2} \mathrm{max}\right)$ and the quadriceps muscle strength $[43,45,46]$.

Exercise capacity can be measured by the anaerobic threshold, which reflects the true aerobic capacity and by the maximal oxygen uptake $\left(\mathrm{VO}_{2}\right.$ peak). To interpret these parameters we have to keep in mind that there are differences between obese and lean subjects. 
Pouwels et al.: Aspects of Exercise before or after Bariatric Surgery: A Systematic Review

Healthy obese subjects undergoing weight loss will experience a decrease in the maximal oxygen uptake and peak work output, because of a decrease of muscle mass [47] and an elevated cardiac stress (which is training for the heart). This cardiac stress will disappear over time [48].

In contrast, many obese patients suffer from obesity-related disorders, such as impaired cardiac function $[49,50]$, inefficient ventilatory work [51], and a decreased fatty acid oxidation $[29,52]$. These disorders are associated with a reduced exercise capacity. During weight loss, both the cardiac and pulmonary systems will restore and may exceed the decrease in muscle mass. This delicate balance might result in the stabilization or even an improvement in maximal oxygen uptake.

Our study has several limitations that have to be taken into account. First, weight loss measured in the included studies was merely self-reported. Ideally, exercise programs and the effects of them must be monitored frequently (and objectively) by visiting a bariatric clinic. Second, because of the small sample sizes of the included studies and the heterogeneity in the reported exercise programs and outcomes, it is difficult to interpret and generalize the findings for the whole bariatric population.

It is well known that exercise programs (with or without bariatric surgery) lead to a decrease in anthropometric parameters, but there are even more beneficial effects of exercise. Future research should be focused on a comparison of different exercise regimes (e.g., endurance and strength) in obese subjects. There is also an increasing need for randomized controlled trials that focus on the effect of peribariatric exercise programs on weight regain after bariatric surgery, because this is still an ongoing problem. Studies by Bond et al. [53] and Li et al. [54] investigate whether or not a preoperative exercise program has effects on the postoperative outcome. The definitive results of those studies are not published yet. Also the long-term effects of exercise programs on QoL, depressive and anxiety symptoms, and eating behavior are not well understood.

\section{Conclusion}

In the majority of reports on exercising in a (future) bariatric population, a positive effect on anthropometrics, cardiovascular risk factors, and physical fitness was described. However, the results were not unanimous, with a wide range of exercise programs and perioperative timing, therefore hampering adequate practical guidance. Summarizing our findings, a beneficial exercise program lasts for a median of 12 weeks, had an intensity of median $65 \%$ peak heart rate $/ \mathrm{VO}_{2}$ max, and is at least partially supervised.

\section{Financial Support}

None

\section{Disclosure Statement}

The authors declare that there is no conflict of interests regarding the publication of this article. 
Pouwels et al.: Aspects of Exercise before or after Bariatric Surgery: A Systematic Review

\section{References}

1 World Health Organization: Obesity: preventing and managing the global epidemic. Report of a WHO consultation. World Health Organization Tech Report Ser 2000;894:i-xii:1-253.

2 Tjepkema M: Adult obesity. Health Reports 2006;17:9-25.

-3 Sturm R: Increases in morbid obesity in the USA: 2000-2005. Pub Health 2007;121:492-496.

4 Picot J, Jones J, Colquitt JL, Gospodarevskaya E, Loveman E, Baxter L, Clegg AJ: The clinical effectiveness and cost-effectiveness of bariatric (weight loss) surgery for obesity: a systematic review and economic evaluation. Health Technol Assess 2009;3:1-190, 215-357, iii-iv.

5 Colquitt JL, Picot J, Loveman E, Clegg AJ: Surgery for obesity. Cochrane Database Syst Rev 2009;2:CD003641.

6 Buchwald H: The evolution of metabolic/bariatric surgery. Obes Surg 2014;24:1126-1135.

-7 Shaw K, Gennat H, O’Rourke P, Del Mar C: Exercise for overweight or obesity. Cochrane Database Syst Rev 2006;4:CD003817.

$>8$ Livhits M, Mercado C, Yermilov I, Parikh JA, Dutson E, Mehran A, Ko CY, Gibbons MM: Exercise following bariatric surgery: SYSTEMATIC review. Obes Surg 2010;20:657-665.

$\checkmark 9$ Egberts K, Brown WA, Brennan L, O’Brien PE: Does exercise improve weight loss after bariatric surgery? A systematic review. Obes Surg 2012;22:335-341.

10 Mosely AM, Herbert RD, Sherrington C: Evidence for physiotherapy practice: a survey of the Physiotherapy Evidence Database (PEDro). Aust J Physiother 2002;48:43-49.

11 Maher CG, Sherrington C, Herbert RD, Moseley AM, Elkins M: Reliability of the PEDro scale for rating quality of randomized controlled trials. Phys Ther 2003;83:713-721.

$\$ 12$ Foley NC, Teasell RW, Bhogal SK, Speechley MR: Stroke rehabilitation evidence-based review: methodology. Top Stroke Rehabil 2003;10:1-7.

13 Altman D: Practical Statistics for Medical Research. London, Chapman and Hall, 1991.

14 Vismara L, Cimolin V, Grugni G, Galli M, Parisio C, Sibilia O, CapodaglioP: Effectiveness of a 6-month homebased training program in Prader-Willi patients. Res Dev Disabil 2010;31:1373-1379.

15 Barbalho-Moulim MC, Miguel GP, Forti EM, Campos Fdo A, Costa D: Effects of preoperative inspiratory muscle training in obese women undergoing open bariatric surgery: respiratory muscle strength, lung volumes, and diaphragmatic excursion. Clinics (Sao Paulo) 2011;66:1721-1727.

-16 Bernhardt V, Lorenzo S, Babb TG, Zavorsky GS: Corrected end-tidal P(CO(2)) accurately estimates $\mathrm{Pa}(\mathrm{CO}(2))$ at rest and during exercise in morbidly obese adults. Chest 2013;143:471-477.

17 Cattano D, Altamirano A, Melnikov V, Pivalizza E, Feldman A, Hagberg C: Postoperative pulmonary inspiratory reserve volume and incentive spirometry in morbidly obese patients undergoing bariatric surgery. J Invest Med 2010;58:678-679.

18 Marzocchi R, Cappellari D, Dalle Grave R, Marchesini G: Massive weight loss without surgery in a super obese patient. Obes Surg 2011;21:540-545.

19 Zapico AG, Benito PJ, Gonzalez-Gross M, Peinado AB, Morencos E, Romero B, Rojo-Tirado MA, Cupeiro R, Szendrei B, Butragueno J, Bermejo M, Alvarez-Sanchez M, Garcia-Fuentes M, Gomez-Candela C, Bermejo LM, Fernandez-Fernandez C, Calderon FJ: Nutrition and physical activity programs for obesity treatment (PRONAF study): methodological approach of the project. BMC Pub Health 2012;12:1100.

20 Adolfsson G: Physical training and weight reduction in connection with operations (in Swedish). Lakartidningen 1970;67:4941-4944.

-21 Sanchez Ortega L, Sanchez Juan C, Garcia AA: Evaluation of a structured program of physical exercise in morbidly obese patients awaiting bariatric surgery (in Spanish). Nutr Hosp 2014;29:64-72.

22 Baillot A, Mampuya W, Comeau E, Meziat-Burdin A, Langlois M: Feasibility and impacts of supervised exercise training in subjects with obesity awaiting bariatric surgery: a pilot study. Obes Surg 2013;23:882-891.

23 Funderburk JA, Callis S: Aquatic intervention effect on quality of life prior to obesity surgery: a pilot study. Annu Ther Recreat 2010;18:66-78.

24 Hickey MS, Gavigan KE, McGammon MR: Effects of 7 days of exercise training on insulin action in morbidly obese men. Clin Exerc Physiol 1999;1:24-28.

-25 Marcon ER, Gus I, Neumann CR. Impact of a minimum program of supervised exercises in the cardiometabolic risk in patients with morbid obesity. Arq Bras Endocrinol Metabol 2011;55:331-338.

26 Shah M, Snell PG, Rao S, Adams-Huet B, Quittner C, Livingston EH, Garg A: High-volume exercise program in obese bariatric surgery patients: a randomized, controlled trial. Obesity (Silver Spring) 2011;19:1826-1834.

$\checkmark 27$ Castello-Simoes V, Polaquini Simoes R, Beltrame T, Bassi D, Maria Catai A, Arena R, Azambuja NC Jr, do Nascimento Ortega J, Borghi-Silva A: Effects of aerobic exercise training on variability and heart rate kinetic during submaximal exercise after gastric bypass surgery - a randomized controlled trial. Disabil Rehabil 2013;35: 334-342.

28 Stegen S, Derave W, Calders P, Van Laethem C, Pattyn P: Physical fitness in morbidly obese patients: effect of gastric bypass surgery and exercise training. Obes Surg 2011;21:61-70.

29 Berggren JR, Boyle KE, Chapman WH, Houmard JA: Skeletal muscle lipid oxidation and obesity: influence of weight loss and exercise. Am J Physiol Endocrinol Metab 2008;294:E726-732.

-30 Baillot A, Audet M, Baillargeon JP, Dionne IJ, Valiquette L, Rosa-Fortin MM, Abou Chakra CN, Comeau E, Langlois MF: Impact of physical activity and fitness in class II and III obese individuals: a systematic review. Obes Rev 2014;15:721-739. 
Pouwels et al.: Aspects of Exercise before or after Bariatric Surgery: A Systematic Review

-31 Fonseca-Junior SJ, Sa CG, Rodrigues PA, Oliveira AJ, Fernandes-Filho J: Physical exercise and morbid obesity: a systematic review. Arq Bras Cir Dig 2013;26(suppl 1):67-73.

-32 Bergmark C, Dewan A, Orsoni A: A novel function of lipoprotein [a] as a preferential carrier of oxidized phospholipids in human plasma. J Lipid Res 2008;49:2230-2239.

-33 Ahmadi N, Tsimikas S, Hajsadeghi F: Relation of oxidative biomarkers, vascular dysfunction, and progression of coronary artery calcium. Am J Cardiol 2010;105:459-466.

-34 Ahmadi N, Eshaghian S, Huizenga R, Sosnin K, Ebrahimi R, Siegel R: Effects of intense exercise and moderate caloric restriction on cardiovascular risk factors and inflammation. Am J Med 2011;124:978-982.

-35 Taylor AJ, Villines TC, Stanek EJ: Extended-release niacin or ezetimibe and carotid intima-media thickness. N Engl J Med 2009;361:2113-2122.

-36 Stieglerand P, Cunliffe A: The role of diet and exercise for the maintenance of fat-free mass and resting metabolic rate during weight loss Sports Med 2006;36:239-262.

-37 Chaston TB, Dixon JB, O’Brien PE: Changes in fat-free mass during significant weight loss: a systematic review. Int J Obes (Lond) 2007;31:743-750.

38 Webster JD, Hesp R, Garrow JS: The composition of excess weight in obese women estimated by body density, total body water and total body potassium. Hum Nutr Clin Nutr 1984;38:299-306.

-39 Maffiuletti N.A, Jubeau M, Munzinger U: Differences in quadriceps muscle strength and fatigue between lean and obese subjects. Eur J Appl Physiol 2007;101:51-59.

-40 Blimkie CJ, Sale DG, Bar-Or O: Voluntary strength, evoked twitch contractile properties and motor unit activation of knee extensors in obese and non-obese adolescent males. Eur J Appl Physiol Occup Physiol 1990;61: 313-318.

41 Pescatello LS, Kelsey BK, Price TB: The muscle strength and size response to upper arm, unilateral resistance training among adults who are overweight and obese. J Strength Cond Res 2007;21:307-313.

42 Hulens M, Vansant G, Lysens R: Study of differences in peripheral muscle strength of lean versus obese women: an allometric approach. Int J Obes Relat Metab Disord 2001;25:676-681.

43 Hulens M, Vansant G, Claessens AL: Predictors of 6-minute walk test results in lean, obese and morbidly obese women. Scand J Med Sci Sports 2003;13:98-105.

44 Tompkins J, Bosch PR, Chenowith R: Changes in functional walking distance and health-related quality of life after gastric bypass surgery. Phys Ther 2008;88:928-935.

45 Laukkanen R, Oja P, Pasanen M: Validity of a two kilometre walking test for estimating maximal aerobic power in overweight adults. Int J Obes Relat Metab Disord 1992;16:263-268.

46 Mattsson E, Larsson UE, Rossner S: Is walking for exercise too exhausting for obese women? Int J Obes Relat Metab Disord 1997;21:380-386.

47 Goran M, Fields DA, Hunter GR: Total body fat does not influence maximal aerobic capacity. Int J Obes Relat Metab Disord 2000;24:841-848.

48 Seres L, Lopez-Ayerbe J, Coll R: Increased exercise capacity after surgically induced weight loss in morbid obesity. Obesity (Silver Spring) 2006;14:273-279.

49 Carroll S, Marshall P, Borkoles E: Efficacy of lifestyle intervention on peak exercise cardiac power output and reserve in premenopausal obese females: a randomised pilot study. Int J Cardiol 2007;119:147-155.

-50 Kanoupakis E, Michaloudis D, Fraidakis O: Left ventricular function and cardiopulmonary performance following surgical treatment of morbid obesity. Obes Surg 2001;11:552-558.

51 Gilbert R, Sipple JH, Auchincloss JH: Respiratory control and work of breathing in obese subjects. J Appl Physiol 1961;16:21-26.

52 Corpeleijn E, Saris WH, Blaak EE: Metabolic flexibility in the development of insulin resistance and type 2 diabetes: effects of lifestyle. Obes Rev 2009;10:178-193.

53 Bond D: Bari-active: a preoperative intervention to increase physical activity. Obes Surg 2011;21:1042.

54 Li C, Zavorsky GS, Kim DJ, Christou NV, Feldman LS, Carli F: Effects of a bariatric preoperative exercise program: a pilot randomized study. Surg Endosc 2013;27(suppl 1):S431. 